\title{
A morte de Atala de Rodolpho Amoêdo e os diálogos entre os romantismos francês e brasileiro
}

\author{
Vitoria Amadio de Oliveira ${ }^{7}$ \\ DOI 10.20396/eha.vil4.3391
}

Este texto foi intitulado "A morte de Atala de Rodolpho Amoêdo e os diálogos entre os romantismos francês e brasileiro", mas, apesar do título escolhido, o quadro de Amoêdo não limita o historiador da arte a pesquisar a interferência de apenas uma corrente artística. Tratar do romantismo foi uma escolha que não compreendemos como limitadora, mas sim expansiva. O romantismo neste quadro fomenta a individualidade do artista e relaciona sua produção com entendimentos bastante modernos, como verificamos ao decorrer da pesquisa. É preciso esclarecer também que a palavra romantismo não será usada para caracterizar Amoêdo, nem seu estilo de pintar, apenas aspectos dentro dos quadros referenciados.

Almejamos compreender o quadro "A morte de Atala" (1883) (figura 1) feito em Paris pelo pintor brasileiro Rodolpho Amoêdo a partir de diversas instâncias: da caracterização dos personagens, da interpretação da cena, das escolhas da composição. Uma destas instâncias se constitui em evidenciar a relação que o quadro apresenta com a literatura, já que ele foi inspirado pelo livro Atala escrito pelo autor francês François-René Chateaubriand em 1801. O livro conta a história do índio Chactas que se apaixona pela mestiça Atala. Impossibilitados de ficarem juntos, o casal foge para a floresta e o protagonista relata estar "completamente indiferente a tudo que não fosse Atala" ${ }^{2}$. Em uma de suas conversas, Chactas descobre que conhece o pai de Atala. Animado pela descoberta, ele expressa desejo de consumar o relacionamento dos dois, mas o cair de uma árvore os interrompe. Nesse momento, eles encontram um homem religioso chamado Padre Aubry, que os acolhe e os leva para a gruta em que mora. Nesta gruta, Atala revela um segredo: sua mãe fez uma promessa que, caso ela sobrevivesse as complicações em seu parto, a filha se manteria virgem até a morte. Temendo quebrar tal promessa no dia anterior, a jovem ingerira veneno, portanto estava prestes a morrer. Ela declara que Chactas “(...) mal sabias que abraçavas a morte, quando beijavas meus la-

\footnotetext{
1 Bacharel em História da Arte da Universidade Federal de São Paulo. Esta publicação faz parte da pesquisa de iniciação científica intitulada "A morte de Atala de Rodolpho Amoêdo e os diálogos entre os romantismos francês e brasileiro”, orientada Profa. Dra. Elaine Dias, que conta com financiamento da Fundação de Amparo à Pesquisa do Estado de São Paulo, processo FAPESP n $2018 / 17618-0$.

2 CHATEAUBRIAND, 1906, p. 1.
} 
bios tremulos!"3. Padre Aubry lhe concede sua última comunhão, numa cena que foi escolhida para a pintura de Amoêdo, e logo após ela falece. O religioso e o índio a enterram posteriormente.

O livro é uma obra clássica dos primórdios do romantismo, que se tornou muito popular na França e no Brasil. Tal popularidade contribuiu para que houvesse uma extensa tradição visual que se refere à Atala. Existe uma grande quantidade de edições ilustradas do livro, incluindo uma pelo famoso desenhista Gustave Doré, assim como uma série de pinturas e esculturas. O quadro de Amoêdo certamente traça diálogos com outras obras de mesma temática, mas podemos também verificar um paralelo com outros quadros pintados durante o século XIX que foram inspirados em livros de literatura romântica.

Um destes paralelos é com o caso das representações visuais de Hiawatha e Minnehaha. Baseadas no poema de 1855 escrito pelo americano Henry Wadsworth Longfellow, elas têm em comum com Atala a presença de índios norte-americanos, o sucesso do objeto literário e, em casos como o da pintura The Death of Minnehaha (1892) de William de Leftwich Dodge (figura 2), o momento em que os personagens são representadas e a posição dos corpos no quadro. O poema trata, dentre outras coisas, da vida do índio Hiawatha e seu relacionamento com Minnehaha. Eles passam por aventuras épicas, até que a jovem morre de fome em um inverno rigoroso. Além do núcleo central dos amantes, existe uma cena que também merece atenção, quando missionários cristãos chegam até os indígenas, num paralelo com a figura de Padre Aubry. Apesar de não existir uma abundância de representações de Minnehaha, é interessante constatarmos como o cenário da pintura de Dodge, assim como as vestes da personagem e até os adereços de Hiawatha se assemeIham com elementos vistos em representações de Atala. Lembremos ainda que ele é de 1892, ou seja, posterior ao de Amoêdo.

Hiawatha declara "all my heart is buried with you"4, quando sua amada falece. Podemos associar essa frase com o sentimento melancólico que invade Chactas depois da morte Atala, tanto nas descrições do livro quanto nas representações visuais em que ele aparece sozinho. Em ambas as histórias, a separação definitiva dos personagens implica em ecos de sofrimento que permanecem com os vivos.

Também são conhecidas as peças de William Shakespeare que tratam de relacionamentos românticos. Os temas de suas peças, ressignificados no século XIX, inspiraram reedições de sua obra, novas montagens de teatro e, naturalmente, muitas pinturas a óleo. Existem diversas pinturas 


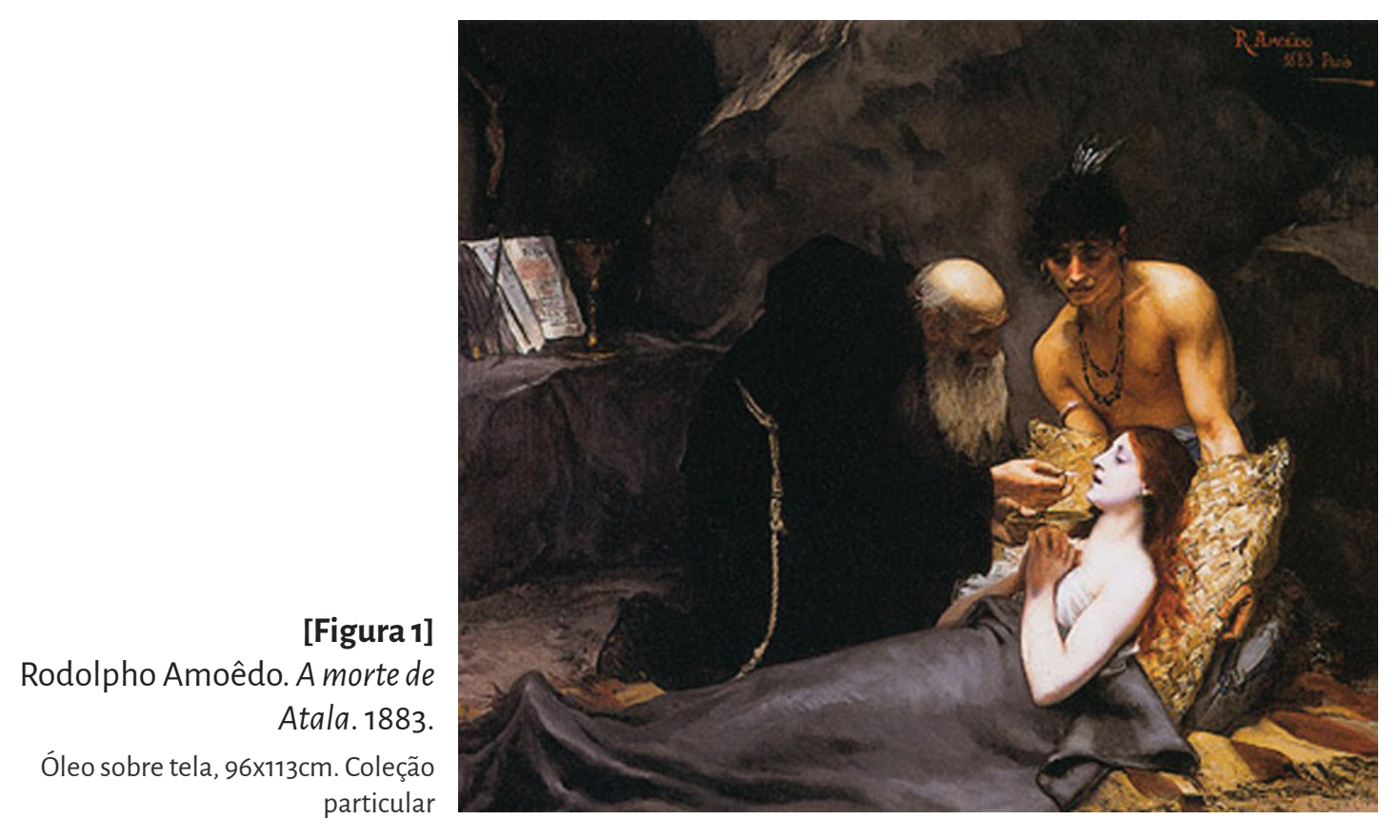

[Figura 2]

William de Leftwich Dodge. The Death of Minnehaha. 1892.

Óleo sobre tela. American Museum of Western Art - The Anschutz Collection, Denver

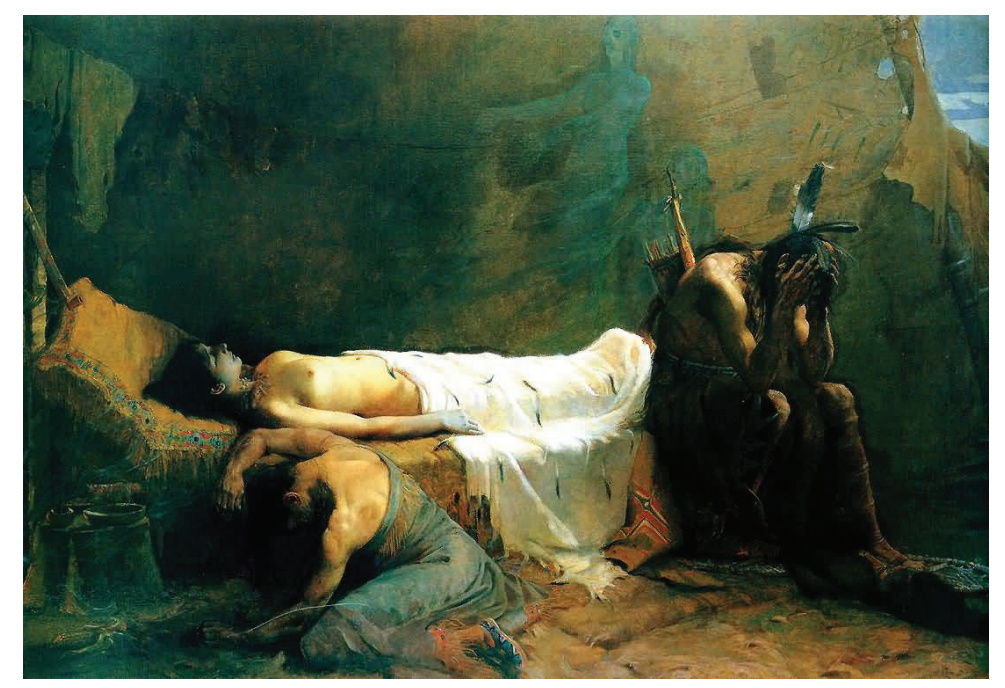

[Figura 3]

Diebolt. The Death of Romeo.

1823.

Óleo sobre tela, $60 \times 73 \mathrm{~cm}$. Coleção particular 
que apresentam o casal Romeu e Julieta vivos, mas também existem obras como The Death of Romeo (1823) Diebolt (figura 3) que mostram Romeu morto. Podemos observar que muitos artistas, como Diebolt, vestem a personagem Julieta de branco, assim como o fazem com a heroína de Chateaubriand. Outra consideração sobre tais obras é que o cabelo de Julieta, como o de outras heroínas românticas, como Atala, por vezes é representado com coloração arruivada.

Além das representações do conhecido casal, vale a pena nos debruçarmos sobre pinturas que tratam de Othello. A peça narra o romance entre Desdêmona e Othello, que desagrada o pai da jovem pelo protagonista se tratar de um mouro. O personagem lago trama para que o casal se separe, incitando desconfiança da fidelidade de Desdêmona. Othello assassina a amada em sua cama em decorrência de tal desconfiança, e ao descobrir que o fez injustamente também se mata. Rodolpho Amoêdo faz uma pintura da protagonista de Shakespeare em 1892 (figura 4). Nela, vemos Desdêmona na cama adormecida com cabelos ruivos que se espalham pelo travesseiro. Ele apresenta a personagem com um apelo sensual, mordendo o lábio inferior e com os seios descobertos, provavelmente referenciando ao seu suposto adultério - ficamos, como observadores, na posição de Othello. Outras Desdêmonas foram feitas em camas, portanto deitadas, em posição análoga às de Atala. Novamente somos levados a nos aproximarmos das representações que transitam entre corpos mortos e adormecidos. Os quadros de Othello por vezes são compostos por uma figura masculina de pele negra ou parda e uma figura feminina de pele branca. Salvo algumas exceções, esse também é o caso de muitas representações de Atala, já que a protagonista, embora mestiça, é normalmente pintada com a pele pálida 5 . Embora ambos os casos tendam mais para o fascínio com qualquer tipo de exótico do que para algum apelo moral, é necessário que consideremos tal fator como relevante já que são duas representações de casais interraciais em voga no momento.

Francesca da Rimini e Paolo Malatesta é outro caso de casais como estes. Na última frase do Canto V do Inferno em A Divina Comédia de Dante Alighieri, o protagonista relata desmaiar após escutar a história dos apaixonados. No segundo círculo do inferno, estão as duas almas sofrendo a punição eterna por seus pecados carnais. Os amores luxuriosos pertencem a um lugar terrível para o poeta, que escreve no século XIV. A popularidade da história aumenta no século XIX. Daniela Di Pasquale aponta para a difusão do canto em Portugal, e sinaliza sobre uma leitura romantizada no período: 
O episódio do v canto do Inferno de Dante Alighieri suscitou sempre nas letras portuguesas grande fascínio e admiração, desde a sua receção criativa quinhentista por parte dos poetas do chamado Inferno dos Namorados no Cancioneiro Ceral de Garcia de Resende, até às óperas líricas dedicadas aos dois amantes de Rimini e encenadas várias vezes nos palcos portugueses do século xix. De facto, no Portugal de Oitocentos, a difusão e a fortuna do mito desta relação extraconjugal foram alimentadas por uma leitura romântica do conto dantesco $(\ldots)^{6}$

Francesca era uma aristocrata italiana concedida em casamento para Giovanni Malatesta. Seu marido supostamente teria uma aparência bastante desagradável, e ela não o amava, mas o irmão dele, Paolo Malatesta, teria sido um jovem atraente. Francesca da Rimini se apaixona por seu cunhado, seu marido os descobre juntos e mata ambos. A história inspirou a passagem citada da "Divina Comédia" e culminou em uma série de representações visuais do casal. Alexandre Cabanel, que foi um dos mestres de Amoêdo em Paris, realiza sua própria versão da história, em uma interpretação bastante teatral (figura 5). Outra figura que também já foi citada que os ilustra é Doré, em decorrência das gravuras que ele realiza para uma nova edição do trabalho do poeta. Existe ainda o caso de um pintor brasileiro que opta por trabalhar com esta iconologia, e opta por mostralos vivos. Aurélio de Figueiredo pinta, no mesmo ano de "A morte de Atala", o quadro "Francesca da Rimini" (figura 6). Nele, vemos Francesca rezando e outros personagens, inclusive Paolo, à esquerda a observando, cercados por um cenário de arquitetura medieval. Consideremos o que o crítico de arte Félix Ferreira tem a dizer sobre o quadro:

O Sr. Aurélio de Figueiredo pôs de lado Dante e foi pedir ao moderno poeta Silvio Pellico inspiração menos lúgubre, ainda que também menos verdadeira, ou natural, reproduzindo o primeiro encontro dos amantes, ou, para melhor, o dia em que Paolo, conforme a sua narrativa da cena segunda do terceiro ato da tragédia, diz ter visto pela primeira vez Francesca, '...atravessando um adro, acompanhada das damas, parar junto a uma nova sepultura e, aí prosternada, levantar mudamente as mãos aos céus'.

Ferreira nos atenta para uma questão séria pertinente às representações literárias, que é a fidelidade às fontes. Quando Figueiredo opta por trocar Dante por Pellico, ele adentra um terreno perigoso. O crítico aponta para outros pontos, como a estatura de Francesca e a linguagem corporal de Paolo, mas no geral o que parece ser mais problemático é o momento escolhido. Vale citar que Ferreira conhecia outras representações do tema, pois as cita no início de seu texto, sendo esta uma

\footnotetext{
6 DI PASQUALE, 2010, p. 173

7 FERREIRA, 1885.
} 
[Figura 4]

Rodolpho Amoêdo. Desdêmo-

na. 1892.

Óleo sobre tela, $97 \times 130.5 \mathrm{~cm}$. Museu Nacional de Belas Artes, Rio de Janeiro

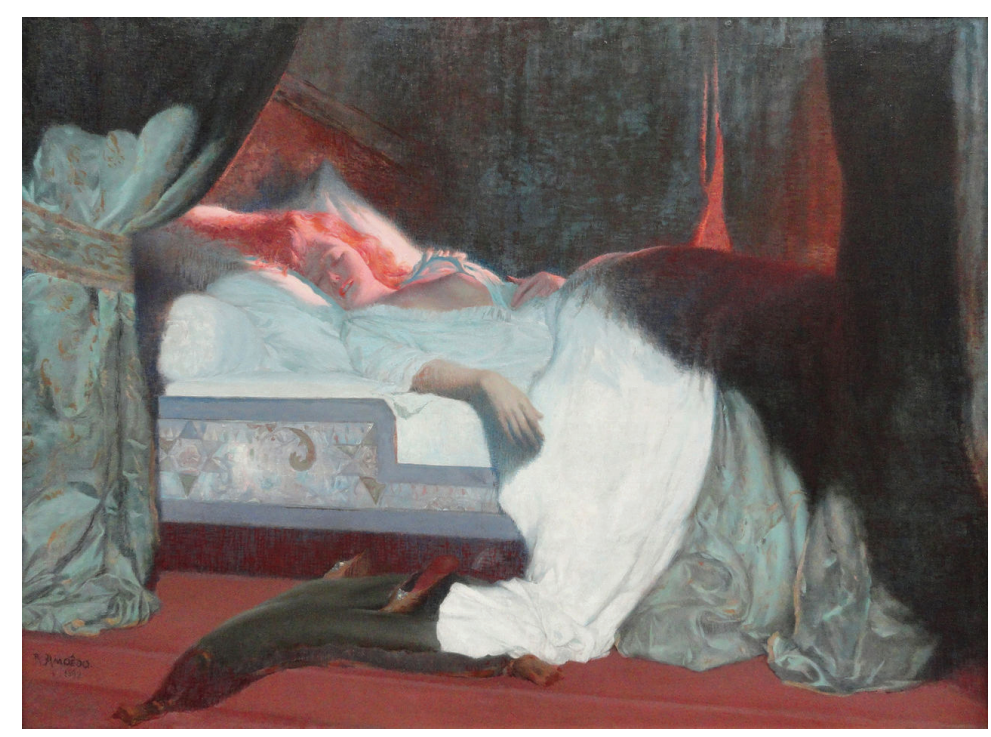

[Figura 5]

Alexandre Cabanel. La mort de Francesca da Rimini et de Paolo Malatesta. 1870. Óleo sobre tela, $184 \times 255 \mathrm{~cm}$. Musée d'Orsay, Paris

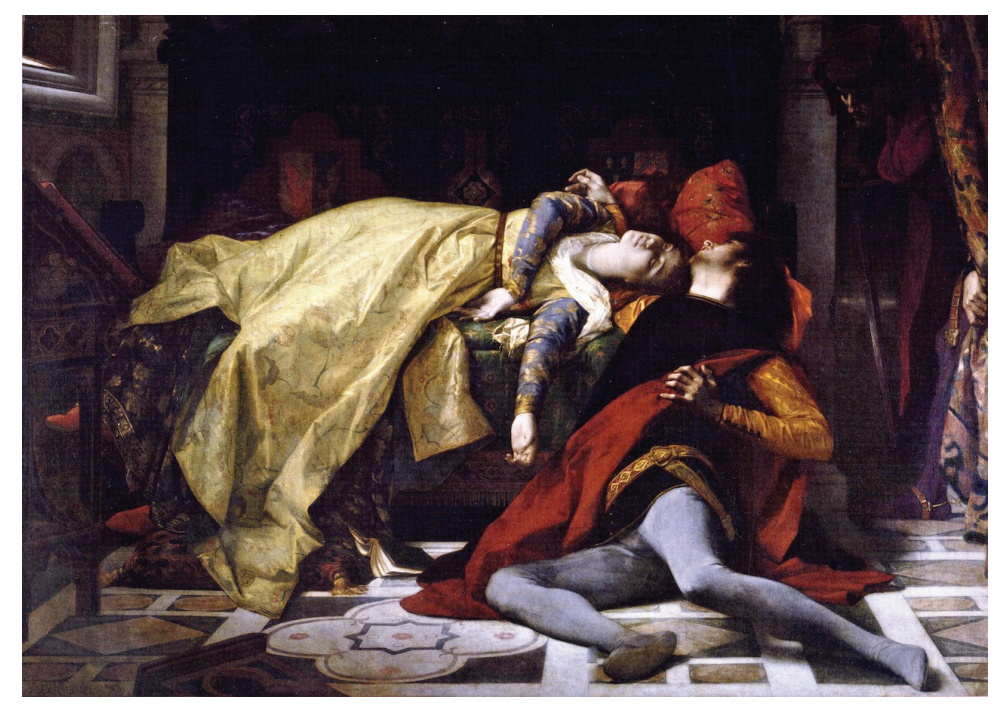

[Figura 6] Aurélio de Figueiredo. Francesca da Rimini. 1883.

Óleo sobre tela, 272 × 206 $\mathrm{cm}$. Museu Nacional de Belas Artes, Rio de Janeiro

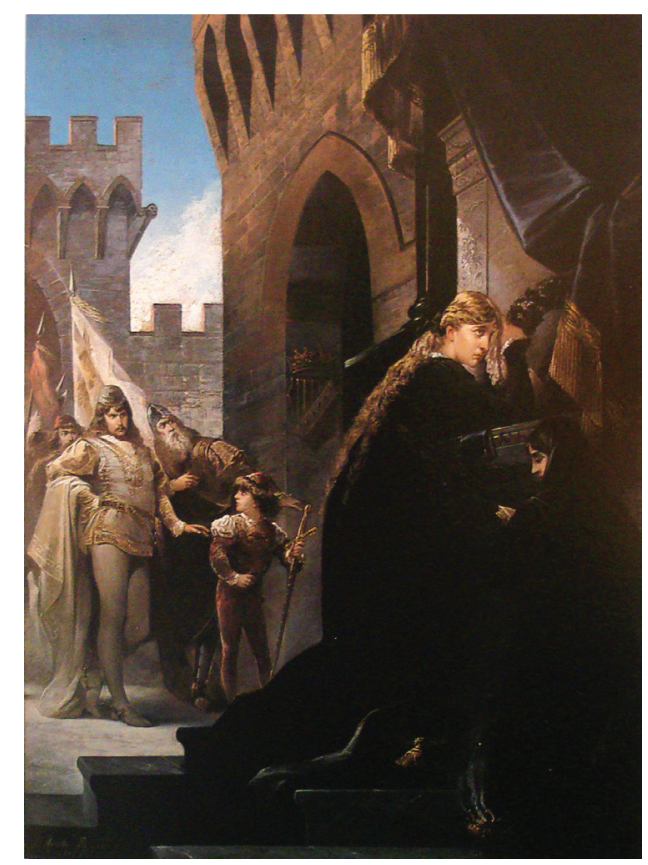


contribuição para nossas hipóteses de que tais modelos circularam em abundância e que, portanto, não só os artistas tinham tais referências em mente, mas os críticos e o público conhecedor de arte também.

Citamos alguns exemplos dessa prática que permeou as artes visuais, e não nos limitamos as obras que possam ter ressoado em A morte de Atala. Consideramos também trabalhos que foram feitos em contextos distintos, porque nos interessa elaborar um referencial visual desse tipo de produção. Embora algumas das obras que compilamos não sejam de uma referência direta, trata-se de um diálogo.

É preciso que verifiquemos também, através da observação destes trabalhos, como o uso da literatura romântica não transpassa um tipo de estilo de pintura específico. Embora tenhamos nos atentado principalmente para as semelhanças entre essas obras, suas diferenças não são desprezíveis. O próprio Rodolpho Amoêdo transitaria por estilos diferentes, e embora tenhamos defendido um caráter romântico em sua pintura, assim como em outras mencionadas, reconhecemos que tal caráter não é "puro". As obras que representam figuras com finais trágicos existem em uma constância temática, e em muitos casos essa é a única coisa que elas têm em comum. A capacidade de transitar entre os estilos não era desfavorável ${ }^{8}$, portanto o romântico, que já era bastante favorável por ligar-se a uma elite intelectual conhecedora das obras literárias, certamente tinha respaldo.

8 Para mais informaç̃̃es sobre esse assunto, checar: PEREIRA, Sonia Comes. Arte brasileira no século XIX. Belo Horizonte: C/ Arte, 2008. 


\section{Referências Bibliográficas}

ALICHIERI, Danta. A divina comédia. Tradução de José Pedro Xavier Pinheiro. 2003. Obra em domínio público, disponível em <http://www.dominiopublico.gov.br/download/texto/ebooooza.pdf>. Acesso em 05 de novembro de 2019.

CARVALHO, Daniela Crepaldi. Madalena: Arquétipo do Pecado. Textos de Teoria Literária de alunos do Instituto de Estudos Literários da Universidade Estadual de Campinas. Disponível em <https://www.unicamp.br/iel/site/alunos/ publicacoes/textos/mooo15.htm>. Acesso em 19 de nov. de 2019.

Catalogue illustré des Salons (Société des artistes français). 1879-1886. Source: Gallica.bnf.fr / Bibliothèque nationale de France

Catálogo da exposição 30 Mestres da pintura no Brasil: 30 anos Credicard. Imprenta: São Paulo : MASP, 2001

Catálogos das Exposições Gerais de Belas Artes (1840-1933). Digitalizados por Carlos Roberto Maciel Levy. Rio de Janeiro: Publicação ArteData, 2003

CAVALCANTI, Ana Maria Tavares. Artistas brasileiros entre territórios: a relação com a Europa e o sentimento de exílio na própria pátria no século XIX. Anais do XIX Encontro da Associação Nacional de Pesquisadores em Artes Plásticas. Entre territórios. Cachoeira (Bahia): ANPAP, p. 49-59, 2010.

CHATEAUBRIAND, François-René. Atala. Tradução de K. d'Avellar. Rio de Janeiro: H. Garnier, 1906.

DI PASQUALE, Daniela. O mito de Francesca da Rimini em Portugal (sécs. XIX-XX): a tradução como testemunho da evolução do cânone-efeitos estranhantes da domesticação e efeitos aculturantes do estranhamento. Babilónia-Revista Lusófona de Línguas, Culturas e Tradução, n. 8/9, 2010.

FERREIRA, Félix. Belas Artes: Estudos e Apreciações. Rio de Janeiro: Baldomero Carqueja Fuentes Editor, 1885, p.142-147. Digitalizado por Carlos Roberto Maciel Levy e disponível em <http://www.artedata.com/crml/museus/crmuso03. htm>. Acesso em 05 de novembro de 2019

LONGFELLOW, Henry Wadsworth. The Song of Hiawatha. 1855. Disponível em <https://www.hwlongfellow.org/poems_ poem.php?pid=294>. Acesso em 8 de novembro de 2019.

MIYOSHI, Alexander Gaiotto. Moema é morta. 2010. Tese (Doutorado em História) - Universidade Estadual de Campinas, Instituto de Filosofia e Ciências Humanas. Campinas, SP.

PEREIRA, Sonia Comes. Arte brasileira no século XIX. Belo Horizonte: C/ Arte, 2008. 